\title{
Sliding Scale Regular Human Insulin for Identifying Critically III Patients Who Require Intensive Insulin Therapy and for Glycemic Control in those with Mild to Moderate Hyperglycemia
}

\author{
Sarah V. Cogle ${ }^{1}$, Susan E. Smith ${ }^{2}$, George O. Maish III ${ }^{3}$, Gayle Minard ${ }^{3}$, Martin A. Croce ${ }^{3}$ \\ and Roland N. Dickerson ${ }^{2,}$
}

${ }^{1}$ Department of Pharmacy Practice, Auburn University Harrison School of Pharmacy, Auburn, AL, ${ }^{2}$ Departments of Clinical Pharmacy and ${ }^{3}$ Surgery, University of Tennessee Health Science Center, Memphis, $T N$, USA

\begin{abstract}
Two sliding scale regular human insulin $(\mathrm{RHI})$ algorithms $(\mathrm{SSI})$ were retrospectively evaluated to identify those who develop severe hyperglycemia (blood glucose $(B G) \geq 180 \mathrm{mg} / \mathrm{dL}$ ) and for glycemic management of continuouslyfed, critically ill trauma patients with mild to moderate hyperglycemia (BG 126 to $179 \mathrm{mg} / \mathrm{dL}$ ). Assignment of low or high SSI was based upon anticipated severity of difficulty in glycemic control. BG was obtained every 3 to 6 hours. Target BG range was 70 to $149 \mathrm{mg} / \mathrm{dL}$. Patients who were unable to achieve a BG<150 mg/dL with SSI and who required a continuous intravenous RHI infusion were identified. Twenty-five of 121 patients (21\%) failed SSI necessitating more intensive insulin therapy. The low and high intensity SSI groups exhibited a baseline BG of $123 \pm 33 \mathrm{mg} / \mathrm{dL}$ and $164 \pm 20$ $\mathrm{mg} / \mathrm{dL}(\mathrm{P}=0.001)$. Average $B G$ for each group was $129 \pm 14 \mathrm{mg} / \mathrm{dL}$ and $145 \pm 21 \mathrm{mg} / \mathrm{dL}(P=0.001)$. Each group spent $20 \pm 4$ and $16 \pm 5$ hours/day within the target $B G$ range $(P=0.001)$, respectively. Mild hypoglycemia $(B G 40-60 \mathrm{mg} / \mathrm{dL})$ occurred in $11 \%$ and $7 \%$ of patients from each group ( $P=$ N.S.). Severe hypoglycemia $(B G<40 \mathrm{mg} / \mathrm{dL}$ ) occurred in zero and two $(5 \%)$ patients, respectively $(P=N . S)$. SSI served as a useful technique to identify those requiring more intensive insulin therapy and was safe and efficacious for continuously-fed, critically ill trauma patients with mild to moderate hyperglycemia.
\end{abstract}

Keywords: Hyperglycemia, hypoglycemia, insulin, critical care, trauma, enteral nutrition, parenteral nutrition.

\section{INTRODUCTION}

Trauma patients frequently experience stressinduced hyperglycemia following injury [1]. Hyperglycemia in critically ill patients with traumatic injuries has been associated with increased morbidity and mortality [2-4]. Much research regarding achievement of glycemic control with continuous intravenous (IV) regular human insulin (RHI) infusion algorithms has been done since the landmark van den Berghe trial [5]. However, increased risk of severe hypoglycemia and worsened outcomes have been demonstrated with use of continuous IV RHI infusions when targeting low blood glucose concentrations (BG) of 80 to $110 \mathrm{mg} / \mathrm{dL}$ [6]. As a result, most guidelines recommend a target blood glucose (BG) range of 140 to $180 \mathrm{mg} / \mathrm{dL}$ for critically ill patients [7-9] although certain critically ill surgical subpopulations including our population with traumatic injuries have been shown to benefit from tighter $B G$ control < 140 to $150 \mathrm{mg} / \mathrm{dL}$ $[3,4,10,11]$.

Although continuous IV RHI infusions are effective in achieving glycemic control, they impart a substantial

*Address of correspondence to this author at the Department of Clinical Pharmacy, University of Tennessee College of Pharmacy, 881 Madison Avenue, Suite 345, Memphis TN 38163, USA; E-mail: rdickerson@uthsc.edu workload burden on nursing personnel, necessitating frequent BG determinations and infusion titrations usually on an hourly basis. In addition, continuous IV $\mathrm{RHI}$ infusions are associated with an increased risk for causing life-threatening hypoglycemia [12] and should be employed only when other viable techniques for glycemic control have failed or are not feasible. Therefore, it is impractical and potentially unsafe to prescribe a continuous IV RHI infusion for all patients in the intensive care unit (ICU) and it becomes necessary to triage which ICU patients will require a continuous infusion. Our approach has been to administer a continuous IV RHI infusion for patients with severe hyperglycemia (BGs $\geq 180 \mathrm{mg} / \mathrm{dL}$ ) [13-15]. It is necessary to also have a surveillance technique to identify patients who develop severe hyperglycemia during incremental increases in carbohydrate intake from advancement of parenteral nutrition (PN) or enteral nutrition (EN) that were not experiencing hyperglycemia prior to nutrition therapy.

We have employed sliding scale RHI therapy (SSI) for identifying continuously-fed, critically ill patients who ultimately require aggressive insulin therapy and for treatment of mild to moderate hyperglycemia [16]. SSI is a method of prescribing a fixed amount of either subcutaneous or IV RHI based on the patient's BG at 
that sampled time. The procedure is typically repeated every 3 to 6 hours depending on the anticipated difficulty in achieving glycemic control. The sliding scale technique has been criticized by others and it has been suggested to completely abandon this methodology for hospitalized patients [17-19]. The recommendation for avoidance of SSI stems from studies where diabetic patients with severe hyperglycemia could not be effectively controlled [1719]. Unfortunately, inattention was paid with respect to severity of the hyperglycemia, etiology (diabetes, stress-induced, or both), nutritional intervention, or the sliding scale dosing regimen itself. As a result, we suggest that lack of attention to these details for many of these studies was a potential cause of these poor results.

We propose that SSI therapy serves a useful technique in clinical practice when used appropriately. Specifically, the aims of this study were to ascertain the frequency of critically ill patients with traumatic injuries would require a continuous IV RHI infusion upon implementation of continuous EN or PN [14] that were not identified prior to initiation of nutrition therapy by use of BG monitoring with the SSI methodology; determine if SSI therapy could effectively manage those who exhibit mild to moderate hyperglycemia (BG 126 to $179 \mathrm{mg} / \mathrm{dL}$ ); and finally, to evaluate if SSI therapy is safe (avoidance of severe hypoglycemia).

\section{METHODS}

Adult patients (> 17 years of age), who were admitted to the Presley Trauma Center of Regional One Health in Memphis, TN from January 2014 until April 2015 and referred to the NSS for continuous enteral nutrition (EN) or parenteral nutrition (PN) were evaluated for potential study inclusion. Patients without severe hyperglycemia ( $B G \geq 180 \mathrm{mg} / \mathrm{dL}$ ) receiving $E N$ or PN were prescribed SSI coverage as part of their routine clinical care. Upon initiation of PN or EN, dextrose was eliminated from large volume parenteral solutions and IV medications whenever possible. Patients were excluded from this study if they: experienced severe hyperglycemia prior to initiation of EN or PN therapy and were given a continuous IV RHI infusion [13,14], received a non-NSS sanctioned SSI regimen prescribed by the primary service, required $<3$ days of the NSS-directed SSI algorithm, received oral anti-diabetic agents or subcutaneous intermediateacting Neutral Protamine Hagedorn (NPH) or longacting (insulin glargine) insulin therapy, or had an adlibitum oral intake during the observation period. Patients were classified as diabetic based on past medical history with receipt of anti-diabetic medications or a plasma hemoglobin $A_{1 c}$ concentration of $>6.5 \%$.

Patients were preferentially given EN via a smallbore nasogastric/nasoenteric feeding tube. PN was given to patients unable to tolerate EN or when EN was contraindicated. Prior to initiation of EN or PN, elimination of dextrose from large volume IV solutions (e.g., D5 $0.45 \% \mathrm{NaCl}$, D5 Ringer's lactate and small volume parenteral medications) was done whenever possible [16]. Patients fed enterally were given a reduced carbohydrate EN formula or a high protein/low calorie EN formula whenever a specialized EN formula (e.g., glutamine/fish oil-containing, fluid restricted, renal failure) was not indicated [20]. Dextrose intake from the PN formulation was restricted to $<4$ to $5 \mathrm{mg} / \mathrm{kg} / \mathrm{min}$ [21]. If EN or PN was temporarily or abruptly discontinued, a $5 \%$ dextrose containing IV fluid was administered at least at the same infusion rate as the EN or PN until nutrition therapy could be resumed in order to prevent hypoglycemia [14].

Patients were assigned by members of the NSS to receive one of two different SSI algorithms based on the perceived need for intensity of the insulin therapy. Patients without a history of diabetes mellitus (DM) and whose baseline BG prior to nutrition therapy was $<150$ $\mathrm{mg} / \mathrm{dL}$ initially received lower intensity SSI (Table 1 ). Patients at higher risk of developing hyperglycemia (those with a history of DM or with stress-induced hyperglycemia and without severe hyperglycemia prior to initiation of nutrition therapy) were assigned to initially receive the higher intensity SSI (Table 1 ). Patients receiving the low intensity SSI were given 2 units of IV RHI for every $25 \mathrm{mg} / \mathrm{dL}$ in BG above 125 $\mathrm{mg} / \mathrm{dL}$ with a ceiling dose of 16 units for a BG > 300 $\mathrm{mg} / \mathrm{dL}$. Patients prescribed higher intensity SSI were given 3 units of IV RHI for every $25 \mathrm{mg} / \mathrm{dL}$ in BG above $125 \mathrm{mg} / \mathrm{dl}$ with a ceiling dose of 24 units for a BG > 300 $\mathrm{mg} / \mathrm{dL}$. Timing of initial BG determinations was done every 3,4 , or 6 hours and was empirically chosen by members of the NSS but could be adjusted and discontinued depending on patient response. Patients who were given the lower intensity SSI regimen had BG monitoring typically every 6 hours whereas those assigned the higher intensity regimen were prescribed BG monitoring every 3 to 4 hours. Point-of-care BG concentrations were determined by the glucose dehydrogenase method using the Accu-Chek ${ }^{\circledR}$ Inform II System (Roche Diagnostics Corporation, Indianapolis, IN, USA).

As the nutrition therapy was progressed towards goal intake, glycemic control was re-evaluated daily by 
Table 1: Intravenous Sliding Scale RHI Algorithms*

\begin{tabular}{|c|c|c|}
\hline BG $\mathbf{~ g g / d L}$ & Lower Intensity SSI & Higher Intensity SSI \\
\hline \hline$<40$ & Give $25 \mathrm{~g}$ D50W IV; call MD & Give 25 g D50W IV; call MD \\
\hline $40-69$ & Give $12.5 \mathrm{~g}$ D50W IV; call MD & 0 units RHI \\
\hline $70-125$ & 0 units RHI & 3 units RHI \\
\hline $126-150$ & 2 units RHI & 6 units RHI \\
\hline $151-175$ & 4 units RHI & 9 units RHI \\
\hline $176-200$ & 6 units RHI & 12 units RHI \\
\hline $201-225$ & 8 units RHI & 15 units RHI \\
\hline $226-250$ & 10 units RHI & 18 units RHI \\
\hline $251-275$ & 12 units RHI & 21 units RHI \\
\hline $276-300$ & 14 units RHI & 24 units RHI; call MD \\
\hline$>300$ & 16 units RHI; call MD & \\
\hline
\end{tabular}

"BG, blood glucose concentration; D50W, 50\% dextrose in water; IV, intravenously; MD, on call resident physician; RHI, regular human insulin; SSI, sliding scale regular human insulin therapy; BG sampling frequency ranges from every $3 \mathrm{~h}$ to $6 \mathrm{~h}$. BG $(\mathrm{mmol} / \mathrm{L})=B G(\mathrm{mg} / \mathrm{dL}){ }^{*} 0.0555$.

the interdisciplinary members of the NSS as part of standard care [16] to ascertain if more intensive insulin therapy was needed. SSI failure was evidenced by escalation to either the higher intensity SSI (for the lower intensity SSI regimen), or initiation of NPH insulin with concurrent SSI, or a continuous IV RHI infusion with discontinuation of the SSI. If patients initially failed lower intensity SSI and were escalated to higher intensity SSI, data were collected for both groups, with each occurrence reported as a separate patient case. SSI was discontinued if $B G$ was maintained in the target $B G$ range $(70 \mathrm{mg} / \mathrm{dL}$ to $149 \mathrm{mg} / \mathrm{dL})$ at goal nutrition intake with minimal $\mathrm{RHI}$ intake (e.g., $\leq \sim 6$ units/d).

The patients' electronic medical record and nutrition support service records were retrospectively reviewed for data retrieval. Data were recorded for a maximum of 8 days following initiation of SSI therapy. Day 0 was a partial day when the SSI and concurrent nutrition therapy was initiated. Serum laboratories were obtained from each patient at approximately 0100 daily and performed by the hospital laboratory as part of routine clinical care. The Injury Severity Score (ISS) [22] was scored by trained nurses according to the American Association for the Surgery of Trauma scales for anatomic injury severity and recorded within the data repository of the Tennessee trauma registry at Regional One Health.

Efficacy of the SSI algorithms was evaluated by mean BG and the number of hours per day spent within the target $B G$ range. Time within or outside the target $B G$ range was calculated based on an assumption that the BG concentration was reflective of the observed time period before the next BG determination. The SSI algorithm was considered successful if BGs were generally maintained within 70 to $149 \mathrm{mg} / \mathrm{dL}$ with no effort by NSS personnel to escalate the current SSI therapy to more aggressive RHI therapy. The SSI algorithm was considered a failure if therapy was escalated to the higher intensity SSI (from the lower intensity SSI regimen) or addition of subcutaneous intermediate-acting Neutral Protamine Hagedorn (NPH) insulin was added [23] or if the SSI was discontinued and a continuous IV RHI infusion $[13,14]$ was initiated. The standard deviation of each patient's mean daily BG concentrations was used as a reflection of the patients' glycemic variability as described by others.[24,25] Safety was assessed by ascertaining the number of patients who experienced at least one episode of mild to moderate hypoglycemia (BG 40 to $69 \mathrm{mg} / \mathrm{dL}$ ) or severe hypoglycemia $(B G<40 \mathrm{mg} / \mathrm{dL}$ ). Any patient who experienced an episode of hypoglycemia was counted once regardless of the number of hypoglycemic episodes for determination of proportion of patients who experienced hypoglycemia.

Data were analyzed using SigmaPlot for Windows version 11.2 (Systat Software Inc., Point Richmond, VA). Data were evaluated for normality of distribution by using the Shapiro-Wilk test. Independent variables were compared by applying the Student's $t$ test for unpaired variables if the data were normally distributed or the Mann-Whitney $U$ test. Differences between groups for categorical data were analyzed by chisquare analysis. Continuous data were expressed as mean \pm standard deviation. A $p$-value $\leq 0.05$ indicated 
statistical significance. The study was approved by and conducted in accordance with the guidelines set forth by the Institutional Review Board at the University of Tennessee Health Science Center and Research Office of Regional One Health (study reference number 14-03437-XM). Since all measurements were performed as part of the routine clinical care, noninterventional, and confidentiality procedures were maintained, the requirement for informed consent was waived.

\section{RESULTS}

\section{Patient Characteristics}

Four hundred and forty-six patients admitted to Regional One Health between January 2014 to April 2015 who were referred to the NSS for EN or PN were evaluated for potential inclusion with a total of 121 cases enrolled in the study (Figure 1). Patients were most commonly excluded from the study if they were treated in non-trauma intensive care units, received non-NSS directed SSI therapy, given < 3 days SSI therapy, required NPH insulin or a continuous IV RHI infusion (Figure 1). Thirty-two of the 446 screened patients $(7 \%)$ required a continuous IV RHI infusion at the time of or prior to starting continuous nutrition therapy due to the presence of a $B G \geq 180 \mathrm{mg} / \mathrm{dL}$. Patient age ranged from 18 to 85 years. Few patients were diabetic $(12 \%)$, received corticosteroids $(0.4 \%)$, or received vasopressors $(0.6 \%)$. A significantly greater proportion of patients who received the higher intensity SSI were concurrently infected $(48 \%$ vs. $18 \% ; \mathrm{P}=$ $0.001)$, had diabetes mellitus ( $24 \%$ vs. $6 \%$; $P=0.013)$, and were older (54 years vs. 45 years; $P=0.016$ ). Specialized nutrition support was initiated $3 \pm 2$ days following admission to the ICU. Other patient characteristics are given in Table 2 .

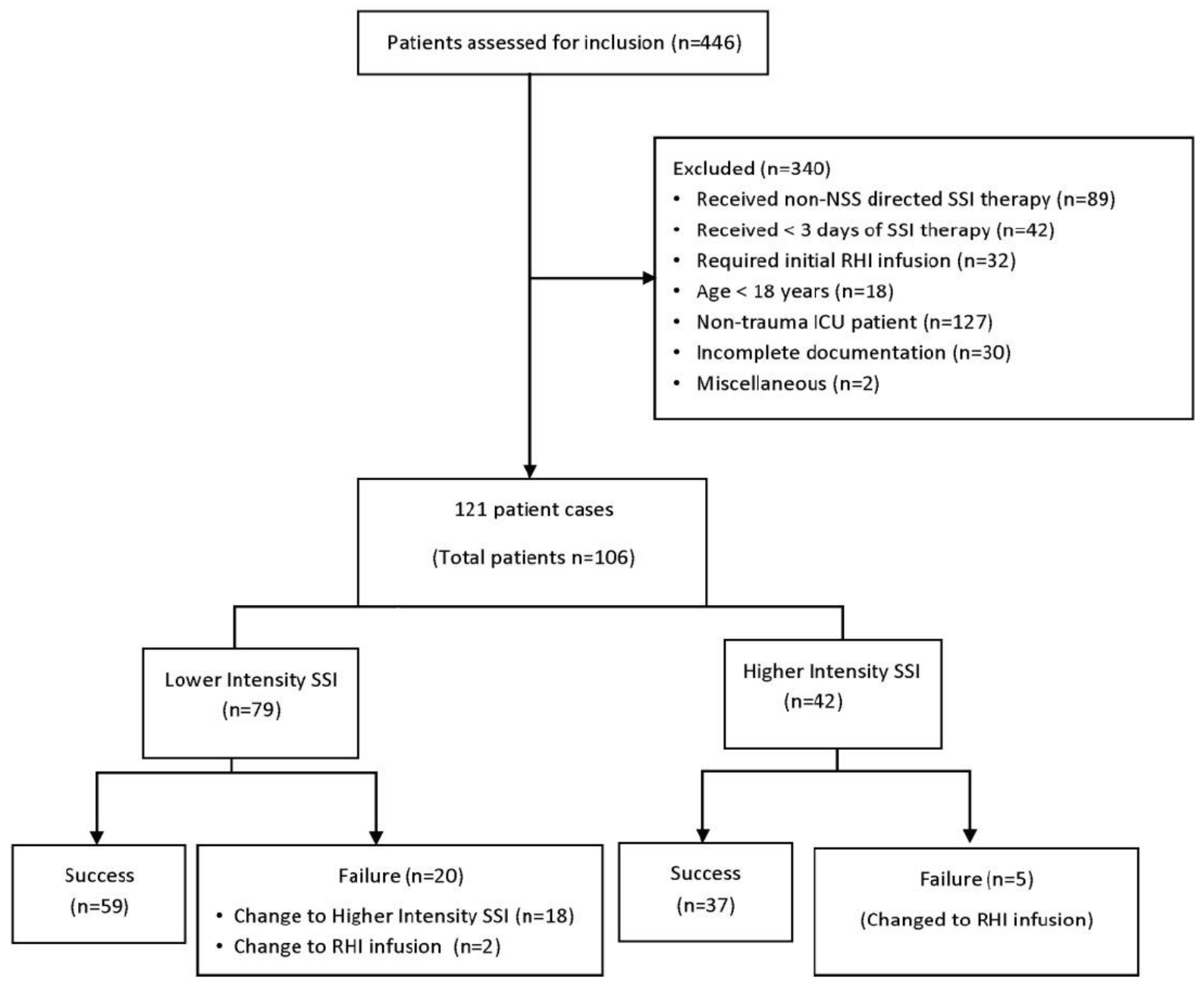

Figure 1: Patient selection and treatment.*

*ICU, intensive care unit; NSS, nutrition support service; RHI, regular human insulin; SSI, sliding scale insulin therapy. Two patients that received SSI classified as miscellaneous were due to have never received EN or PN $(n=1)$ or readmission to the trauma intensive care unit and previously evaluated $(n=1)$. 


\section{Efficacy and Safety of SSI Therapy}

A total of 25 of 121 patients (21\%) failed initial SSI therapy necessitating a more intensive insulin regimen. When stratified by SSI intensity, 20 of 79 patient cases (25\%) failed lower intensity SSI and 5 of 42 patient cases $(12 \%)$ failed higher intensity SSI. Seven of the 121 patients $(6 \%)$ who initially received SSI therapy required a continuous intravenous insulin infusion. Four patients $(5 \%)$ in the lower intensity group were assigned more frequent BG observations than every 6 hours (e.g., every 3 or 4 hours) as opposed to 30 $(71 \%)$ patients in the higher intensity group $(P=0.001)$. Time spent in the target BG range was $16 \pm 5$ hours per day for the higher intensity SSI group and $20 \pm 4$ hours per day for the lower intensity $\mathrm{SSI}$ group ( $\mathrm{P}=$ 0.001 ; Table 3 ). The higher intensity group required 16 \pm 10 units of $\mathrm{RHI}$ per day, while the lower intensity group required $4 \pm 4$ units of $\mathrm{RHI}$ per day $(\mathrm{P}=0.001$; Figure 2 and Table 3). Twenty one of 106 non-diabetic

Table 2: Patient Characteristics*

\begin{tabular}{|c|c|c|c|}
\hline Variable & Lower Intensity SSI & Higher Intensity SSI & $\mathbf{P}$ \\
\hline $\mathrm{N}$ & 79 & 42 & \\
\hline Age, y & $45 \pm 18$ & $54 \pm 18$ & 0.016 \\
\hline Sex, Male/Female, n/n & $63 / 16$ & $30 / 12$ & 0.420 \\
\hline $\begin{array}{c}\text { Race } \\
\text { African American, n } \\
\text { Caucasian, } \mathrm{n} \\
\text { Hispanic/Other, n }\end{array}$ & $\begin{array}{l}27 \\
39 \\
13\end{array}$ & $\begin{array}{c}10 \\
26 \\
6\end{array}$ & 0.584 \\
\hline $\begin{array}{l}\text { Admit Diagnosis } \\
\text { Assault/fall } \\
\text { GSW/KSW } \\
\text { MVA } \\
\text { Other }\end{array}$ & $\begin{array}{c}13 \\
12 \\
50 \\
4\end{array}$ & $\begin{array}{c}5 \\
4 \\
32 \\
1\end{array}$ & 0.532 \\
\hline Injury Severity Score & $30 \pm 14$ & $26 \pm 10$ & 0.231 \\
\hline Traumatic brain injury, $\mathrm{n}$ & $43(54 \%)$ & $31(74 \%)$ & 0.059 \\
\hline Concurrent infection, $\mathrm{n}$ & $14(18 \%)$ & $20(48 \%)$ & 0.001 \\
\hline $\mathrm{BMI}, \mathrm{kg} / \mathrm{m}^{2}$ & $28.5 \pm 6.9$ & $29.1 \pm 5.6$ & 0.611 \\
\hline Weight, kg & $87 \pm 23$ & $89 \pm 19$ & 0.559 \\
\hline Diabetes mellitus, $n$ & $5(6 \%)$ & $10(24 \%)$ & 0.013 \\
\hline WBC, cells $/ \mathrm{mm}^{3}$ & $13.5 \pm 14.5$ & $13.5 \pm 7.0$ & 0.998 \\
\hline C-reactive protein, $\mathrm{mg} / \mathrm{L}$ & $25.4 \pm 11.4$ & $25.5 \pm 10.0$ & 0.984 \\
\hline Initial Tmax $\left({ }^{\circ} \mathrm{C}\right)$ & $38.6 \pm 0.7$ & $38.6 \pm 0.6$ & 0.658 \\
\hline Initial SUN, mg/dL & $21 \pm 14$ & $15 \pm 9.1$ & 0.006 \\
\hline Initial serum creatinine, $\mathrm{mg} / \mathrm{dL}$ & $0.9 \pm 0.4$ & $1.0 \pm 0.9$ & 0.632 \\
\hline Prealbumin, mg/dL & $8.7 \pm 4.7$ & $8.9 \pm 3.8$ & 0.859 \\
\hline Albumin, g/dL & $2.5 \pm 0.5$ & $2.5 \pm 0.3$ & 0.684 \\
\hline EN/PN, n/n & $68 / 11$ & $35 / 7$ & 0.346 \\
\hline Day NS started, d & $3 \pm 2$ & $3 \pm 2$ & 0.560 \\
\hline Mortality, n & $12(15 \%)$ & $9(21 \%)$ & 0.522 \\
\hline Hospital length of stay, $d$ & $30 \pm 17$ & $33 \pm 20$ & 0.410 \\
\hline ICU length of stay, $d$ & $18 \pm 10$ & $21 \pm 15$ & 0.307 \\
\hline Ventilator days, $d$ & $14 \pm 10$ & $19 \pm 19$ & 0.069 \\
\hline
\end{tabular}

*BG, blood glucose concentration; BMI, body mass index; EN, enteral nutrition; GSW, gunshot wound; KSW, knife stab wound; ICU, intensive care unit; MVA, motor vehicle accident; N, number; NS, nutrition support; PN, parenteral nutrition, SSI, sliding scale regular human insulin therapy; SUN, serum urea nitrogen; Tmax, maximum temperature; WBC, white blood cell count. Serum C-reactive protein $(\mathrm{nmol} / \mathrm{L})=$ serum C-reactive protein $(\mathrm{mg} / \mathrm{L}) *{ }^{*} 9.524 ;$ serum creatinine $($ umol/L) $=$ serum creatinine $(\mathrm{mg} / \mathrm{dL}) * 88.4$; serum urea nitrogen $(\mathrm{mmol} / \mathrm{L})=$ serum urea nitrogen $(\mathrm{mg} / \mathrm{dL})^{*} 0.357$ 
Table 3: Glycemic Response to Sliding Scale RHI therapy*

\begin{tabular}{|c|c|c|c|}
\hline Variable & Lower Intensity SSI & Higher Intensity SSI & $\mathbf{P}$ \\
\hline $\mathrm{N}$ & 79 & 42 & \\
\hline Carbohydrate intake, $\mathrm{g} / \mathrm{d}$ & $144 \pm 145$ & $137 \pm 73$ & 0.792 \\
\hline $\mathrm{RHI}$ intake, units/d & $4 \pm 4$ & $16 \pm 10$ & 0.001 \\
\hline Baseline BG, mg/dL & $123 \pm 33$ & $164 \pm 20$ & 0.001 \\
\hline BG during SSI, mg/dL & $129 \pm 14$ & $145 \pm 21$ & 0.001 \\
\hline $\mathrm{BG}$ variability $^{\mathrm{a}}, \mathrm{mg} / \mathrm{dL}$ & $13.2 \pm 9.6$ & $14.7 \pm 11.3$ & 0.124 \\
\hline \#BGs/day & $3.4 \pm 1.6$ & $5.2 \pm 1.4$ & 0.001 \\
\hline BG $70-149 \mathrm{mg} / \mathrm{dL}, \mathrm{h} / \mathrm{d}$ & $20 \pm 4$ & $16 \pm 5$ & 0.001 \\
\hline$B G \geq 150 \mathrm{mg} / \mathrm{dL}, \mathrm{h} / \mathrm{d}$ & $4 \pm 4$ & $8 \pm 5$ & 0.001 \\
\hline BG $40-69 \mathrm{mg} / \mathrm{dL}, \mathrm{h} / \mathrm{d}$ & $0.1 \pm 0.3$ & $0.1 \pm 0.5$ & 0.735 \\
\hline $\mathrm{BG}<40 \mathrm{mg} / \mathrm{dL}, \mathrm{h} / \mathrm{d}$ & $0 \pm 0$ & $0.0 \pm 0.2$ & 0.109 \\
\hline Patients with BG $40-69 \mathrm{mg} / \mathrm{dL}, \mathrm{n}$ & $9(11 \%)$ & $3(7 \%)$ & 0.540 \\
\hline Patients with $B G<40 \mathrm{mg} / \mathrm{dL}, \mathrm{n}$ & $0(0 \%)$ & $2(5 \%)$ & 0.119 \\
\hline
\end{tabular}

${ }^{*} B G$, blood glucose concentration; h, hours; N, number; RHI, regular human insulin; SSI, sliding scale regular human insulin therapy. BG (mmol/L) = BG (mg/dL) *0.0555.

${ }^{a}$ Average standard deviation of the daily mean blood glucose concentration (mean SD $\pm S D$ ).

patients (20\%) compared to 4 out of 15 patients with diabetes $(27 \%)$ failed initial SSI therapy $(P=N S)$. Figure 2 illustrates mean BGs for both SSI groups remain close to the target range and appear to converge by day 4 of therapy. With an increase in carbohydrate intake as the EN or PN was progressed towards goal intake, $\mathrm{RHI}$ dosage also escalated which resulted in an overall decrease in BG for the higher intensity regimen. BGs for the lower intensity regimen appeared to be stable on a daily basis throughout the observation period with concurrent escalation of carbohydrate and $\mathrm{RHI}$ intake (Figure 2).

Target BG concentrations were achieved for most patients in both SSI intensity groups without a significant amount of hypoglycemia. Three patients (7\%) experienced at least one episode of mild hypoglycemia and two patients (5\%) experienced an episode of severe hypoglycemia (BG $<40 \mathrm{mg} / \mathrm{dL}$ ) in the higher intensity group. Nine patients $(11 \%)$ from the lower intensity group experienced at least one episode of mild hypoglycemia and none experienced severe hypoglycemia. No patients had documented hypoglycemic symptoms.

\section{DISCUSSION}

Hyperglycemia is a common occurrence when providing specialized nutrition support to critically ill patients[26,27] and if left untreated, can lead to significant detrimental clinical outcomes $[2,3,5,10]$. In recent years, there has been much discussion regarding the optimal $B G$ target range for critically ill patients, although keeping $B G<140$ to $150 \mathrm{mg} / \mathrm{dL}$ has been associated with improved clinical outcomes in critically ill patients with severe traumatic injuries $[3,5,6,10]$. Continuous IV RHI infusions have historically been recommended to achieve glycemic control for critically ill patients [7]; however, they impart a significant demand upon nursing workload, require frequent monitoring and titration, and if not titrated correctly can cause profound hypoglycemia $[6,15,28]$. As a result, some institutions including ours [16], have routinely implemented the use of SSI therapy in patients without severe hyperglycemia whom require $E N$ or PN. The intention for use of this mode of BG monitoring and insulin therapy has two primary purposes. First, it can be used to identify those patients who may experience severe hyperglycemia during advancement of carbohydrate-containing EN or PN. Secondly, SSI may also serve as a means to manage patients who exhibit mild to moderate hyperglycemia during continuous nutrition therapy.

Our data indicated SSI monitoring was successful in identifying patients who became hyperglycemic during advancement of nutrition therapy that were not severely hyperglycemic prior to initiation of PN or EN. SSI monitoring identified that $21 \%$ of patients whom the Nutrition Support Service prescribed SSI therapy needed to be transitioned to intensive insulin therapy. For those critically ill patients with traumatic injuries 

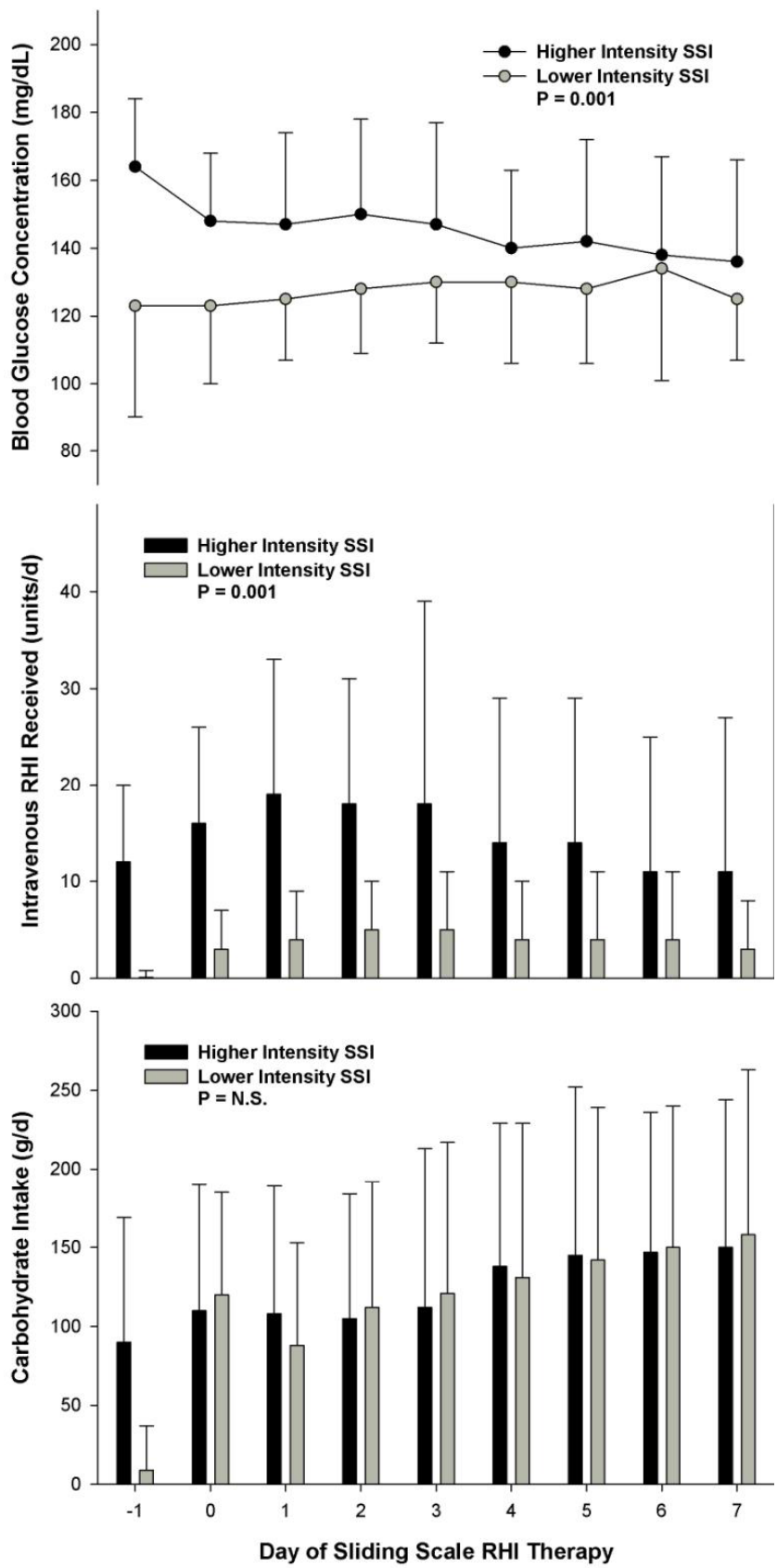

Figure 2: Glycemic response to the higher and lower intensity sliding scale regular human insulin therapy (SSI) during specialized nutrition support.

who only experienced mild to moderate hyperglycemia during continuous nutrition therapy, SSI was effective for the majority of patients. BG concentrations in the target range were achieved for an average duration of 20 and 16 hours daily for the lower and higher intensity SSI regimens, respectively $(P=0.001$, Table 3 ). However, despite a significantly lower duration of time spent in the BG target range by the higher intensity SSI group, these data should not be misinterpreted to indicate that the lower intensity SSI regimen was more efficacious than the higher intensity SSI algorithm. This disparity was attributed to differences in patient population between groups. Patients who received the higher intensity SSI algorithm had a significantly greater baseline BG (164 versus $123 \mathrm{mg} / \mathrm{dL}, \mathrm{P}=$ $0.001)$ prior to initiation of nutrition therapy, a higher prevalence of diabetes mellitus $(24 \%$ vs. $6 \% ; \mathrm{P}=$ $0.001)$, and a greater incidence of concurrent infection (48\% vs. $18 \% ; P=0.001)$ compared to the lower intensity group, respectively (Tables $\mathbf{2}$ and $\mathbf{3}$ ). Additionally, patients who received the higher intensity SSI regimen were prescribed more frequent BG monitoring, received more insulin, and had a trend towards more BG variability (Table 3 ). Thus, the population who received the higher intensity SSI would have been anticipated to have greater difficulty in achieving glycemic control than the lower intensity regimen.

Our results for achieving glycemic control with SSI are divergent from the majority of literature that suggests SSI is ineffective in the management of hyperglycemia for hospitalized patients [17-19]. Our divergent data that favors utility in use of SSI may be explained by multiple factors. Many studies that indicated the lack of success with use of SSI were conducted in patients with severe hyperglycemia and with diabetes [29-35] or had a significant proportion of diabetics in their population [36-40]. In contrast to these studies, only $12 \%$ of our population who received SSI therapy had diabetes and none had severe hyperglycemia at initiation of PN or EN. Patients with diabetes and severe hyperglycemia prior to initiation of continuous nutrition therapy were given a continuous IV $\mathrm{RHI}$ infusion[14] and were excluded from study entry. The low incidence of diabetes mellitus in our study population is important to interpreting our data as critically ill, hyperglycemic patients with diabetes who receive continuous $E N$ or $P N$ exhibit more $B G$ variability, require more insulin, and may not achieve similar effectiveness in glycemic control when compared to non-diabetics with stress-induced hyperglycemia [14]. In contrast to our study, the majority of published studies examining efficacy of SSI made no effort to exclude severely hyperglycemic patients with the exception of some studies excluding those with diabetic ketoacidosis or hyperosmolar nonketotic coma. Studies reporting failure of SSI therapy included patients whose baseline BG exceeded 180 $\mathrm{mg} / \mathrm{dL}$, with the average initial BG concentrations ranging from $178 \mathrm{mg} / \mathrm{dL}$ to $229 \mathrm{mg} / \mathrm{dL}$ $[29,30,32,33,36,38-40]$ in contrast to $123 \mathrm{mg} / \mathrm{dL}$ and $164 \mathrm{mg} / \mathrm{dL}$ for our SSI dosing algorithms.

All patients in this study were ICU patients and required intense BG monitoring every 3 to 6 hours 
while nutrition therapy was being initiated and advanced to goal. In contrast, some previous studies excluded patients in the ICU $[32,33,36,39]$ with less frequent BG monitoring and less insulin dosing opportunities to reduce hyperglycemia $[35,38,41]$. The most commonly reported BG determination interval for SSI dosing from the literature is every 6 hours [29$31,35,37,39]$. With more frequent BG monitoring, patients who fail SSI and who require more intensive insulin therapy can be identified sooner. In addition, patients can receive $\mathrm{RHI}$ doses more frequently in an effort to maintain glycemic control.

The success or failure of SSI therapy may also be attributable to the dosage design of the SSI regimen itself. Most published SSI algorithms do not prescribe short-acting insulin therapy until the BG is greater than 150 or $200 \mathrm{mg} / \mathrm{dL}[29-31,35,37,39]$. The usual initial dosage of $\mathrm{RHI}$ or insulin aspart in other published algorithms is 2 units and the dosage is escalated by an additional 2 units for every $50 \mathrm{mg} / \mathrm{dL}$ increase in BG above the baseline $B G$ intervention range [29$31,35,37,39]$. In contrast, the SSI algorithms employed in our practice are more intensive with incremental increases in $\mathrm{RHI}$ dosage by either 2 or 3 units for every $25 \mathrm{mg} / \mathrm{dL}$ above a BG of $125 \mathrm{mg} / \mathrm{dL}$ (Table 1). Therefore, in addition to our stringent patient selection and exclusion criteria for who receives SSI, our efficacy in glycemic control may also be partially attributed to more intensive insulin dosing and BG monitoring.

Safety of our SSI algorithms are evident by the low incidence of hypoglycemia (Table 3). None of the patients in the lower intensity SSI and two patients $(5 \%)$ in the higher intensity SSI group experienced an episode of severe hypoglycemia (BG $<40 \mathrm{mg} / \mathrm{dL}$ ). It may be argued that some patients in the low intensity SSI may not have required insulin therapy due to the $11 \%$ incidence of mild to moderate hypoglycemia (BG 40 to $69 \mathrm{mg} / \mathrm{dL}$ ) despite receiving only an average of 4 units/day. These data indicate that it is difficult to anticipate who will or will not require insulin therapy during advancement of the carbohydrate-containing nutrition regimen for this population, as $21 \%$ of patients whom SSI therapy was thought to be adequate actually required more intensive insulin therapy and $10 \%$ of all patients receiving SSI therapy experienced an episode of mild to moderate hypoglycemia.

This study has limitations. Data were collected retrospectively and decisions regarding selection for initial SSI therapy and/or escalation in insulin therapy were at the careful discretion of the interdisciplinary
NSS. Patients with severe hyperglycemia at initiation of $\mathrm{PN}$ or EN were excluded from the analysis due to early identification and provision of more aggressive insulin therapy. The rationale for receiving less than 3 days of SSI without escalation to more aggressive insulin therapy was most likely due to achievement of goal nutrition intake without the need for a significant amount of insulin supplementation as it is common practice to discontinue SSI therapy under these circumstances at our institution. Eighteen patients who failed the lower intensity SSI and given the higher intensity SSI group resulted in inclusion in both groups which may be a source of error in the data. The assumption was made that a single BG concentration reflected the $B G$ for the entire time period until the next BG determination. This assumption may be erroneous particularly if the patient was given $\mathrm{RHI}$ therapy in response to the BG concentration. Not all patients achieved BG concentrations within the target range for the entire day. The low and high intensity SSI regimens were able to achieve target BG concentrations for a mean of 20 and 16 hours daily, respectively. However, this duration of glycemic control is favorable considering that even a continuous IV RHI infusion or subcutaneous NPH with SSI averages 20 and 15 hours daily, respectively, in a continuously-fed, trauma ICU population with severe hyperglycemia $[14,23]$. Finally, it is unknown whether use of SSI for controlling mild to moderate hyperglycemia improves clinical outcomes during critical illness following traumatic injury and requires further study.

\section{CONCLUSIONS}

Despite bias against the use of SSI in inpatient settings, there is no evidence to refute the role of SSI therapy as a means for identifying critically ill patients who develop severe hyperglycemia (BG > $180 \mathrm{mg} / \mathrm{dL}$ ) requiring intensive insulin therapy or for management of mild to moderate hyperglycemia during continuous EN or PN therapy. Prescribing SSI ensures that BG concentrations are assessed frequently to facilitate evaluation for initiation of change in the current glycemic control methodology to a more aggressive regimen. For those who do not require escalation to a more aggressive regimen, our intermittent $\mathrm{RHI}$ sliding scale algorithms are safe and effective for controlling mild to moderate hyperglycemia for the majority of critically ill patients with traumatic injuries who require continuous nutrition therapy. SSI is a viable mode of therapy for achieving glycemic control in patients who are not at highest risk for severe hyperglycemia. 


\section{ACKNOWLEDGEMENT}

There was no funding source. This study was presented, in part, at the Fifteenth Annual Nutrition Week of the American Society for Parenteral and Enteral Nutrition. January 17, 2016. Austin, TX, USA

\section{REFERENCES}

[1] Black PR, Brooks DC, Bessey PQ, Wolfe RR, Wilmore DW. Mechanisms of insulin resistance following injury. Ann Surg 1982; 196: 420-35. https://doi.org/10.1097/00000658-198210000-00005

[2] Bochicchio GV, Sung J, Joshi M, Bochicchio K, Johnson SB, Meyer W, Scalea TM. Persistent hyperglycemia is predictive of outcome in critically ill trauma patients. J Trauma 2005; 58: 921-4.

https://doi.org/10.1097/01.TA.0000162141.26392.07

[3] Collier B, Diaz J, Jr., Forbes R, et al. The impact of a normoglycemic management protocol on clinical outcomes in the trauma intensive care unit. JPEN J Parenter Enteral Nutr 2005; 29: 353-9.

https://doi.org/10.1177/0148607105029005353

[4] Scalea TM, Bochicchio GV, Bochicchio KM, Johnson SB, Joshi M, Pyle A. Tight glycemic control in critically injured trauma patients. Ann Surg 2007; 246: 605-12. https://doi.org/10.1097/SLA.0b013e318155a789

[5] van den Berghe $G$, Wouters $P$, Weekers $F$, et al. Intensive insulin therapy in the critically ill patients. N Engl J Med 2001; 345: 1359-67. https://doi.org/10.1056/NEJMoa011300

[6] Finfer S, Chittock DR, Su SY, et al. Intensive versus conventional glucose control in critically ill patients. $\mathrm{N}$ Engl J Med 2009; 360: 1283-97.

https://doi.org/10.1056/NEJMoa0810625

[7] American Diabetes Association. Standards of medical care in diabetes- 2016. Diabetes Care 2016; 39: S1-S112.

[8] McClave SA, Taylor BE, Martindale RG, et al. Guidelines for the Provision and Assessment of Nutrition Support Therapy in the Adult Critically III Patient: Society of Critical Care Medicine (SCCM) and American Society for Parenteral and Enteral Nutrition (A.S.P.E.N.). JPEN J Parenter Enteral Nutr 2016; 40: 159-211.

https://doi.org/10.1177/0148607115621863

[9] McMahon MM, Nystrom E, Braunschweig C, et al. A.S.P.E.N. clinical guidelines: nutrition support of adult patients with hyperglycemia. JPEN J Parenter Enteral Nutr 2013; 37: 23-36. https://doi.org/10.1177/0148607112452001

[10] Bochicchio GV, Joshi M, Bochicchio KM, et al. Early hyperglycemic control is important in critically injured trauma patients. J Trauma 2007; 63: 1353-9. https://doi.org/10.1097/TA.0b013e31815b83c4

[11] Jacobi J, Bircher N, Krinsley J, et al. Guidelines for the use of an insulin infusion for the management of hyperglycemia in critically ill patients. Crit Care Med 2012; 40: 3251-76. https://doi.org/10.1097/CCM.0b013e3182653269

[12] Anon. Joint Commission IDs five high-alert meds. ED Manag 2000; 12: 21-2.

[13] Dickerson RN, Lynch AM, Maish GO, 3rd, Croce MA, Minard G, Brown RO. Improved safety with intravenous insulin therapy for critically ill patients with renal failure. Nutrition 2014; 30: 557-62.

https://doi.org/10.1016/j.nut.2013.10.010

[14] Dickerson RN, Swiggart CE, Morgan LM, Maish III GO, Croce MA, Minard G, Brown RO. Safety and efficacy of a graduated intravenous insulin infusion protocol in critically ill trauma patients receiving specialized nutritional support. Nutrition 2008; 24: 536-45.

https://doi.org/10.1016/j.nut.2008.02.008
[15] Dickerson RN, Hamilton LA, Connor KA, Maish GO, 3rd, Croce MA, Minard G, Brown RO. Increased hypoglycemia associated with renal failure during continuous intravenous insulin infusion and specialized nutritional support. Nutrition 2011; 27: 766-72. https://doi.org/10.1016/j.nut.2010.08.009

[16] Dickerson RN, Maish GO, 3rd, Minard G, Brown RO. Nutrition support team-led glycemic control program for critically ill patients. Nutr Clin Pract 2014; 29: 534-41. https://doi.org/10.1177/0884533614530763

[17] Baldwin D, Villanueva G, McNutt R, Bhatnagar S. Eliminating inpatient sliding-scale insulin: a reeducation project with medical house staff. Diabetes Care 2005; 28: 1008-11. https://doi.org/10.2337/diacare.28.5.1008

[18] Hirsch IB. Sliding scale insulin--time to stop sliding. JAMA 2009; 301: 213-4. https://doi.org/10.1001/jama.2008.943

[19] Umpierrez GE, Palacio A, Smiley D. Sliding scale insulin use: myth or insanity? Am J Med 2007; 120: 563-7. https://doi.org/10.1016/j.amjmed.2006.05.070

[20] Kudsk KA, Minard G, Croce MA, et al. A randomized trial of isonitrogenous enteral diets after severe trauma. An immuneenhancing diet reduces septic complications. Ann Surg 1996; 224: 531-43.

https://doi.org/10.1097/00000658-199610000-00011

[21] Rosmarin DK, Wardlaw GM, Mirtallo J. Hyperglycemia associated with high, continuous infusion rates of total parenteral nutrition dextrose. Nutr Clin Pract 1996; 11: 151-6. https://doi.org/10.1177/0115426596011004151

[22] Baker SP, O'Neill B, Haddon W, Jr., Long WB. The injury severity score: a method for describing patients with multiple injuries and evaluating emergency care. J Trauma 1974; 14: 187-96.

https://doi.org/10.1097/00005373-197403000-00001

[23] Dickerson RN, Wilson VC, Maish GO, 3rd, Croce MA, Minard G, Brown RO. Transitional NPH insulin therapy for critically ill patients receiving continuous enteral nutrition and intravenous regular human insulin. JPEN J Parenter Enteral Nutr 2013; 37: 506-16. https://doi.org/10.1177/0148607112458526

[24] Krinsley JS. Glycemic variability: a strong independent predictor of mortality in critically ill patients. Crit Care Med 2008; 36: 3008-13 https://doi.org/10.1097/CCM.0b013e31818b38d2

[25] Meyfroidt G, Keenan DM, Wang X, Wouters PJ, Veldhuis JD, Van den Berghe $G$. Dynamic characteristics of blood glucose time series during the course of critical illness: effects of intensive insulin therapy and relative association with mortality. Crit Care Med 2010; 38: 1021-9.

https://doi.org/10.1097/CCM.0b013e3181cf710e

[26] Shaw JH, Wolfe RR. An integrated analysis of glucose, fat and protein metabolism in severely traumatized patients. Studies in the basal state and the response to total parenteral nutrition. Ann Surg 1989; 209: 63-72. https://doi.org/10.1097/00000658-198901000-00010

[27] Dickerson RN, Johnson JL, Maish GO, 3rd, Minard G, Brown RO. Evaluation of nursing adherence to a paper-based graduated continuous intravenous regular human insulin infusion algorithm. Nutrition 2012; 28: 1008-11. https://doi.org/10.1016/j.nut.2012.01.010

[28] Preiser JC, Devos P, Ruiz-Santana S, et al. A prospective randomised multi-centre controlled trial on tight glucose control by intensive insulin therapy in adult intensive care units: the Glucontrol study. Inten Care Med 2009; 35: 1738-48. https://doi.org/10.1007/s00134-009-1585-2

[29] Dickerson LM, Ye X, Sack JL, Hueston WJ. Glycemic control in medical inpatients with type 2 diabetes mellitus receiving sliding scale insulin regimens versus routine diabetes medications: a multicenter randomized controlled trial. Ann Fam Med 2003; 1: 29-35. https://doi.org/10.1370/afm.2 
[30] Queale WS, Seidler AJ, Brancati FL. Glycemic control and sliding scale insulin use in medical inpatients with diabetes mellitus. Arch Intern Med 1997; 157: 545-52. https://doi.org/10.1001/archinte.1997.00440260101014

[31] Alfonso A, Koops MK, Mong DP, Vigersky RA. Glycemic control with regular versus lispro insulin sliding scales in hospitalized Type 2 diabetics. J Diabetes Complications 2006; 20: 153-7. https://doi.org/10.1016/j.jdiacomp.2005.06.009

[32] Umpierrez GE, Smiley D, Jacobs S, et al. Randomized study of basal-bolus insulin therapy in the inpatient management of patients with type 2 diabetes undergoing general surgery (RABBIT 2 surgery). Diabetes Care 2011; 34: 256-61. https://doi.org/10.2337/dc10-1407

[33] Umpierrez GE, Smiley D, Zisman A, et al. Randomized study of basal-bolus insulin therapy in the inpatient management of patients with type 2 diabetes (RABBIT 2 trial). Diabetes Care 2007; 30: 2181-6.

https://doi.org/10.2337/dc07-0295

[34] Golightly LK, Jones MA, Hamamura DH, Stolpman NM, McDermott MT. Management of diabetes mellitus in hospitalized patients: efficiency and effectiveness of slidingscale insulin therapy. Pharmacotherapy 2006; 26: 1421-32. https://doi.org/10.1592/phco.26.10.1421

[35] Emam IA, Allan A, Eskander $\mathrm{K}$, et al. Our experience of controlling diabetes in the peri-operative period of patients who underwent cardiac surgery. Diabetes Res Clin Pract 2010; 88: 242-6.

https://doi.org/10.1016/j.diabres.2010.03.002

[36] Korytkowski MT, Salata RJ, Koerbel GL, et al. Insulin therapy and glycemic control in hospitalized patients with diabetes during enteral nutrition therapy: a randomized controlled clinical trial. Diabetes Care 2009; 32: 594-6. https://doi.org/10.2337/dc08-1436

[37] Cook A, Burkitt D, McDonald L, Sublett L. Evaluation of glycemic control using NPH insulin sliding scale versus insulin aspart sliding scale in continuously tube-fed patients. Nutr Clin Pract 2009; 24: 718-22. https://doi.org/10.1177/0884533609351531

[38] Datta S, Qaadir A, Villanueva G, Baldwin D. Once-daily insulin glargine versus 6-hour sliding scale regular insulin for control of hyperglycemia after a bariatric surgical procedure: a randomized clinical trial. Endocr Pract 2007; 13: 225-31. https://doi.org/10.4158/EP.13.3.225

[39] Schroeder JE, Liebergall M, Raz I, Egleston R, Ben Sussan G, Peyser A, Eldor R. Benefits of a simple glycaemic protocol in an orthopaedic surgery ward: a randomized prospective study. Diabetes Metab Res Rev 2012; 28: 71-5. https://doi.org/10.1002/dmrr.1217

[40] Becker T, Moldoveanu A, Cukierman T, Gerstein HC. Clinical outcomes associated with the use of subcutaneous insulinby-glucose sliding scales to manage hyperglycemia in hospitalized patients with pneumonia. Diabetes Res Clin Pract 2007; 78: 392-7.

https://doi.org/10.1016/j.diabres.2007.05.003

[41] Hagelberg A, Ivert T, Efendic S, Ohrvik J, Anderson RE. Insulin glargine improves glycaemic control after coronary surgery in patients with diabetes or pre-diabetes. Scand Cardiovasc J 2008; 42: 71-6. https://doi.org/10.1080/14017430701721756

Received on 23-05-2017

Accepted on 29-06-2017

Published on 14-07-2017

\section{DOI: https://doi.org/10.6000/1927-5951.2017.07.03.6}

(c) 2017 Cogle et al.; Licensee Lifescience Global.

This is an open access article licensed under the terms of the Creative Commons Attribution Non-Commercial License (http://creativecommons.org/licenses/by-nc/3.0/) which permits unrestricted, non-commercial use, distribution and reproduction in any medium, provided the work is properly cited. 